\title{
Violência contra a mulher: Atuação do psicólogo às vítimas
}

\author{
Violence against Women: Psychologist's performance to victmis
}

\author{
Carolina Monsores da Silva ${ }^{\dagger}$, Naiara Paula dos Santos Campos ${ }^{\dagger *}$, Thais Leite Reis ${ }^{\S}$
}

Como citar esse artigo. DA SILVA, C.M; CAMPOS, N.P.S.; REIS, T.L. A violência contra a mulher: Atuação do psicólogo às vítimas. Revista Mosaico, v.11, n.1, p. 100-106, 2020.

\section{Resumo}

Objetiva-se neste artigo, aclarar sobre a violência contra a mulher e a atuação do psicólogo no contexto de violência doméstica. Utilizou-se como metodologia a revisão de literatura da temática. Procura-se demonstrar que a violência doméstica se caracteriza como uma forma de violência de gênero. Bem como, discorrer que essa violência se constitui como ações perpetradas no âmbito interpessoal e/ou relacional, tendo como alvo sumário a mulher. Considerando que a violência não ocorre em plano recente, mas que vem acontecendo há décadas. Ainda se explana o papel do psicólogo nos atendimentos à mulher e também ao agressor. Pretende-se compreender a violência contra as mulheres em seu amparo legal e promover uma reflexão de seus efeitos, a fim de ressignificar suas vidas.

Palavras-chave: Violência Doméstica. Psicologia. Ressignificação.

\section{Introdução}

Buscou-se com este trabalho aclarar sobre a violência contra mulher e a atuação do psicólogo nesse tipo de atendimento. Demonstrando que a violência contra a mulher se constitui em um fenômeno social persistente e multiforme que revela a violação dos direitos humanos e a relação de desigualdade entre homens e mulheres existentes em nossa sociedade. Suas manifestações estabelecem uma relação de submissão e de poder, implicando em situações de medo, isolamento, dependência e intimidação da mulher. É entendida como uma ação que envolve o uso da força real ou simbólica, por parte de alguém, com a finalidade de submeter o corpo e a mente à vontade e a liberdade de outrem (BANDEIRA, 2014, p. 460).
Dentro deste aspecto, o psicólogo precisa compreender seu papel nesse tipo de auxílio prestado às mulheres vítimas desse tipo de agressão, baseado em violência de gênero que compreende em agressões de caráter psicológico, patrimonial, físico, sexual e podem resultar na morte de mulheres por suicídio ou por homicídio. A violência doméstica, conforme contextualiza a Lei Maria da Penha, é assinalada pela prática de abusos e violações de direitos, que ocorrem no seio familiar, praticado pelos próprios membros residentes no mesmo lugar, como os esposos; pais ou filhos; entre outros (MORAES; SILVA; AVIZ, 2017, p. 2).

Compreende-se a relevância do tema abordado na atual conjuntura de um elevado índice de violência doméstica noticiado nas mídias. Por isso, justifica-se neste estudo trazer uma reflexão ajuizada sobre a Lei

Afiliação dos autores:

${ }^{\dagger}$ Graduanda em Psicologia, Universidade de Vassouras, Vassouras, RJ, Brasil

$\S$ Especialista em Psicologia Clínica Existencial do Rio de Janeiro - IFEN, Universidade de Vassouras ,Vassouras, RJ, Brasil

* Email de correspondencia: naiarapaulasantoscampos@gmail.com 
$\mathrm{n}^{\circ} 11.340 / 2006$, nomeada como Lei Maria da Penha, que se tornou um marco na luta e proteção aos direitos das mulheres, pois tem como objetivo proibir e prevenir qualquer forma de violência doméstica e familiar (BRASIL, 2006).

Em consonância ao tema, observa-se também que avanços legais foram adotados, a fim de dar à devida proteção a mulher em situação de violência. Nesse sentido, a Lei $n^{\circ} 13.104 / 2015$ passa a prever o Feminicídio como circunstância qualificadora do crime de homicídio e o incluir como crimes hediondos (BRASIL, 2015).

Desse modo, o trabalho tem como objetivo discutir a violência contra a mulher, evidenciando tal violência caracterizada hoje, como violência de gênero feminicídio. Bem como, discorrer que tal violência, que vem acontecendo há décadas, constitui-se como ações perpetradas no âmbito interpessoal e/ou relacional, tendo como alvo sumário a mulher. Ainda pretendeu-se explanar sobre o papel do psicólogo no atendimento à situação de violência vivenciada por muitas mulheres, que tem sido considerada um dos principais problemas que atinge a população mundial. Por fim, pretendeuse compreender a violência de gênero em seu amparo legal.

Buscou-se ao longo do trabalho, em um primeiro momento explicar a Lei Maria da Penha, para que se tenha uma compreensão melhor da gravidade do problema de violência doméstica e buscar uma compreensão sobre a violência de gênero e seus efeitos. No segundo momento, elucidar de forma clara e sucinta sobre o papel do psicólogo no auxílio às mulheres em situação de violência doméstica.

Procurou-se também, comentar sobre o papel do psicólogo no auxílio aos agressores, a fim de trazer uma sensibilização e responsabilidade, quando esses agressores demonstram interesse na reestruturação do relacionamento conjugal. Procurou-se também, aclarar sobre a importância de a mulher encontrar caminhos que a levem à superação, e tenham assim, condições psicológicas de conviver numa sociedade machista.

Como resultado do trabalho buscou-se a promoção de uma reflexão mais apurada do psicólogo frente ao seu papel no atendimento das mulheres em situação de violência doméstica, segundo os aspectos interpessoal ou relacional, praticadas pelos membros que habitam no ambiente familiar. Bem como, uma reflexão no âmbito da violência de gênero - Feminicídio, como sendo crime hediondo em conformidade com a Lei 13.104/2015, observando que tal violência não ocorreu somente em caráter recente.

Utilizou-se como metodologia para a construção deste estudo, a revisão de literatura, para embasamento teórico sobre a temática escolhida.

\section{Discorrendo sobre a Lei Maria da Penha.}

Desde os mais remotos tempos, as mulheres sofreram e vem sofrendo diversos tipos de violência sejam de ordem física, moral, psicológica, sexual ou patrimonial. Ao longo dos anos movimentos sociais se levantaram a favor de tornar visível a violência contra a mulher. Na década de 70 , por meio do movimento "feminista", a violência começou a ganhar visibilidade e a ser tratada como um "problema social". A partir desse momento as brigas entre marido e mulher, que ninguém deveria "meter a colher", saem do particular e passam ao público, onde o Estado e a sociedade devem "meter a colher" e denunciar (CORTIZO; GOYNECHE, 2010; GUEDES JÚNIOR; RIBEIRO, 2018, p. 3).

A violência doméstica é uma relação de poder e dominação do homem sobre a mulher oriunda de uma construção ao longo dos anos, constituindo-se assim em um problema sociocultural baseado no domínio do "patriarcado" (GUEDES JÚNIOR; RIBEIRO, 2018, p. $3)$.

Dentro desta perspectiva histórica, surge no cenário brasileiro a Lei Maria da Penha criando mecanismos com a intenção de coibir e prevenir todo o tipo de violência doméstica e familiar contra a mulher (BRASIL, 2006).

Evidencia Fernandes (ANO apud OLIVEIRA, 2015) que a Lei Maria da Penha foi criada em decorrência da farmacêutica cearense Maria da Penha Maia Fernandes ter vivenciado violência doméstica, tendo como agressor seu próprio esposo, que tentou por duas vezes matá-la. Maria da Penha foi uma das tantas mulheres em situação de violência doméstica espalhadas na sociedade e que não se intimidou lutando bravamente por vinte anos até ver o seu agressor condenado, segundo o seu relato; em consequência desta violência Maria da Penha ficou paraplégica após receber o tiro.

De acordo com Oliveira (2015), Maria da Penha transformou-se em um "baluarte do movimento feminista na luta por uma legislação penal mais rigorosa na repressão aos delitos que envolvessem as diversas formas de violência doméstica e familiar contra a mulher" (OLIVEIRA, 2015, p. 27). A Lei Maria da Penha foi criada com o objetivo de resguardar e amparar as mulheres contra todos os tipos de violência, buscando ações e mecanismos que visam impedir a violência de gênero, com a finalidade de coibir a violência contra a mulher, seja no âmbito doméstico, familiar e social, eliminando todo o tipo de discriminação que a mulher venha a ser vítima (BRASIL, 2006).

As medidas de proteção preveem não somente a punição ao agressor, mas também a assistência psicológica do serviço social e jurídica às mulheres em situação de violência. (BRASIL, 2006). Dentro deste 
aspecto, a fim de esclarecimento, a Lei Maria da Penha, descreve em seu capítulo II, no Artigo $7^{\circ}$, as formas de violência doméstica e familiar que as mulheres podem ser submetidas, a saber:

(I) Violência física - é aquela violência entendida como qualquer conduta que ofenda a integridade ou saúde corporal da mulher;

(II) Violência psicológica - é aquela violência entendida como qualquer conduta que cause dano emocional e diminuição da autoestima, perturbando o pleno desenvolvimento ou degradando ou controlando as ações da mulher;

(III) Violência sexual - é aquela violência entendida como qualquer conduta que constranja a presenciar, a manter ou a participar de relação sexual sem o consentimento da mulher, mediante intimidação, ameaça, coação ou uso de força;

(IV) Violência patrimonial - é aquela violência entendida como qualquer conduta que configure retenção, subtração, destruição parcial ou total dos objetos, instrumentos de trabalho, documentos pessoais etc., contra a mulher;

(V) Violência moral - é aquela entendida como qualquer conduta que configure calúnia, difamação ou injúria contra a mulher (BRASIL, 2006).

Durante décadas a cultura machista perpetua e reforça a hegemonia masculina sobre o feminino, este que sempre foi visto como de menor valor social e figura inútil ao capital justifica-se a invisibilidade de seus corpos. Neste aspecto, a Lei Maria da Penha, surgiu como um importante dispositivo legal representando a proteção na busca da garantia dos direitos da mulher em situação de violência (GUEDES JÚNIOR; RIBEIRO, 2018, p. 1).

\section{Compreendendo a violência de gênero e seus efeitos.}

Vale a pena ressaltar que, mediante tudo o que foi exposto, baseado nas teorias dos autores que aclararam sobre o tema, observa-se que a violência pode ser compreendida em:

(1) Violência de Gênero é quando a pessoa sofre algum tipo de violência baseado no seu sexo, que impacta negativamente a sua vida, exercendo poder em sua identidade, bem-estar social, físico ou psicológico;

(2) Violência Doméstica é quando a pessoa sofre algum tipo de violência praticada entre os membros que habitam um mesmo ambiente familiar em comum, ou seja, entre pessoas que de certa forma, apresentam algum tipo de laço familiar (pais e filhos - marido e esposa genro e sogra), desse modo, a violência doméstica pode assumir diversos tipos de "agressões" - incluindo abusos físicos, verbais, emocionais, econômicos, religiosos, reprodutivos, sexuais etc.;
(3) Violência contra a Mulher é o tipo de violência em que a mulher sofre resultando em sua morte ou mesmo acarretando em lesão física, sexual ou psicológica - são violências que as mulheres sofrem, exclusivamente pelo fato de serem mulheres - $\mathrm{a}$ fim de combater tal violência no Brasil é que em 2015, foi criada a Lei n ${ }^{\circ} 13.104 / 2015$ alterando o código penal, qualificando o "Feminicídio" como crime hediondo, aumentando a pena do agressor (CASIQUE; FUREGATO, 2006).

Neste aspecto, após a compreensão acima, vale ressaltar que o conceito que se tem de gênero foi cogitado inicialmente, pela antropologia e também pela psicanálise, demonstrando que nessas relações estabelecidas considerando o gênero feminino e masculino, estão baseadas nos papéis que ambos exercem dentro da própria sociedade, papéis de cunho social distinto e hierárquico, portanto desigual (KARLINSKI, 2012, p. 27). Segundo Teles e Melo (2003) a definição de violência de gênero deve ser entendida como uma relação de poder de dominação do homem e de submissão da mulher. Ele demonstra que os papéis impostos às mulheres e aos homens, consolidados ao longo da história e reforçado pelo patriarcado, induzem relações violentas entre os sexos e indica que a prática desse tipo de violência não é fruto da natureza, mas sim do processo de socialização das pessoas (TELES; MELO, 2003, p.18; MOREIRA; BORIS; VENÂNCIO, 2011, p. 399).

Os costumes, a educação e os meios de comunicação tratam de criar e preservar estereótipos que reforçam a ideia de que o sexo masculino tem o poder de controlar os desejos, as opiniões e a liberdade de ir vir das mulheres. (TELES; MELO, 2003, p.18; MOREIRA; BORIS; VENÂNCIO, 2011, p. 399).

Leonore Walker (2018) autora clássica da temática da violência contra a mulher descreveu um ciclo de violência, delimitando-o em três fases: a tensão, explosão e lua de mel. Vale ressaltar que as fases variam tanto em intensidade como no tempo, para o mesmo casal e entre diferentes casais e não aparecem, necessariamente, em todos os relacionamentos. Neste aspecto, compreende-se as fases da seguinte forma:

A $1^{\text {a }}$ fase é conhecida como a fase do acúmulo de tensão, em que inicia-se o estresse com incidentes menores. É a fase das discussões, das demonstrações de ciúmes exagerados e destruições de objetos pessoais, para a autora, essa fase pode ter a duração de uma questão de semanas, meses ou anos.

A $2^{\text {a }}$ fase é caracterizada como a fase da agressão (fase da explosão). Nesta fase, o acúmulo de tensão faz culminar com agressões físicas, espancamento, xingamentos, em que toda carga de estresse é descarregada. $\mathrm{O}$ agressor tem como características o descontrole e a imprevisibilidade e qualquer atitude da mulher pode tornar-se motivo para novas agressões do campo físico, psicológico ou sexual. 
Finalizando, a $3^{\text {a }}$ fase do ciclo chama-se fase da reconciliação, uma espécie de nova lua de mel. Aqui o agressor tem uma crise de arrependimento, passando a ter um comportamento amoroso, carinhoso e promete que jamais o comportamento violento repetir-se-á.

Nesta $3^{\circ}$ fase o agressor se utiliza de várias estratégias de manipulação de cunho afetivo, prometendo inúmeras juras de amor, fazendo com que a mulher, durante essa fase, não denuncie, por acreditar nas mudanças que estão acontecendo. Porém, após esse aparente período de tranquilidade o ciclo recomeça e volta tudo outra vez, perpetuando-se o ciclo da violência. Para o devido rompimento desse ciclo de violência, é necessário que a mulher esteja plenamente ciente de sua situação, procurando ajuda emocional com o profissional (WALKER, 2018, p. 1).

Segundo as Referências Técnicas para Atuação de Psicólogas (os) em Programa de Atenção à Mulher em situação de Violência do Conselho Federal de Psicologia (CFP, 2013), as fases deste ciclo são caracterizadas pelo aumento da tensão psicológica e das agressões físicas, que muitas vezes resultam em espancamento ou mesmo na morte da mulher.

Entre essas fases ocorrem períodos temporários de reconciliação, marcados pelo comportamento extremamente gentil do autor de violência, que muitas vezes afirma se sentir arrependido por suas ações. Quando ocorrem os episódios de violência psicológica, as ameaças e humilhações verbais podem ser dirigidas tanto à mulher como a outros membros da família, especialmente aos filhos.

A fim de criminalizar o homicídio de mulheres motivado pelo simplesmente pelo fato de serem mulheres foi promulgada a Lei de $\mathrm{n}^{\circ} 13.104$ de 2015 (BRASIL, 2015). Nesta perspectiva, o Feminicídio prevê uma pena para o homicídio, considerado qualificado, entre 12 a 30 anos de reclusão e ainda o aumento da pena em $1 / 3 \mathrm{em}$ seu Parágrafo $7^{\circ}$, se o referido crime for praticado: (I) durante a gestação ou nos 3 meses após ao parto; (II) contra pessoa menor de 14 anos, maior de 60 anos e pessoa com deficiência; (III) na presença de descendente ou ascendente a vítima (PEREIRA; PEREIRA, 2017, p. 1).

\section{O papel do psicólogo no atendimento às mulheres em situação de violência doméstica}

O profissional psicólogo entra no cenário brasileiro no serviço de saúde pública, bem no final dos anos 1970 e início de 1980, abrindo dessa forma, uma amplitude até então conhecida na esfera clínica, agora sua atuação encontra novas oportunidades na esfera do atendimento social na saúde pública (MONTEIRO, 2012, p.20).
O psicólogo tanto deve ter os conhecimentos voltados para a esfera social, como também, nas concepções teóricas de atuação clínica. É nesse sentido, que surge o conceito de clínica ampliada, pois o indivíduo não pode ser vislumbrado sem antes levar em consideração sua história de vida e o meio social em que ele está devidamente inserido (MONTEIRO, 2012).

Neste conceito de clínica ampliada, segundo preconiza Monteiro (2012), o profissional psicólogo tem a oportunidade de amplitude em seu atendimento, diversificando "seu trabalho clínico, ampliando seu foco de intervenção, passando para a comunidade, saindo do seu consultório para introduzir-se em diversas instituições e comunidades, atendendo pessoas de várias classes sociais, criando e adaptando suas estratégias de intervenção" (MONTEIRO, 2012, p. 20).

Neste aspecto, esta atuação profissional contextualizada socialmente pode abarcar um maior número de mulheres em seus territórios que estejam em situação de violência, por meio dos equipamentos de proteção resgatando a autoestima, fortalecendo a dignidade e autonomia, a fim de tomarem para si o protagonismo de suas vidas (GUEDES JÚNIOR; RIBEIRO, 2018).

De acordo com a Lei Maria da Penha, em seu Artigo $7^{\circ}$, no inciso II, preceitua que: "a violência psicológica, entendida como qualquer conduta que lhe cause dano emocional e diminuição da autoestima ou que lhe prejudique e perturbe o pleno desenvolvimento", visando de certa forma, a degradação ou até mesmo, o controle total ou parcial de "suas ações, comportamentos, crenças e decisões, mediante ameaça, constrangimento, humilhação, manipulação, isolamento, vigilância constante, perseguição contumaz, insulto, chantagem, violação de sua intimidade", ou até mesmo, no âmbito das agressões que ridicularizam, exploram, limitando o seu "direito de ir e vir, ou qualquer outro meio que the cause prejuízo à saúde psicológica e à autodeterminação" (BRASIL, 2006). Cabe ao psicólogo no atendimento à mulher facilitar a compreensão da crença cristalizada que reforça a violência, onde muitas vezes, "ela passa a se sentir merecedora das agressões, considerando justa ou natural a forma pela qual é tratada pelo parceiro" (GUEDES JÚNIOR; RIBEIRO, 2018, p. 9).

Dentro desta perspectiva, o profissional dever ter uma postura clínica no atendimento dessa clientela que sofre agressão psicológica, a postura clínica se relaciona muito mais com a atitude do profissional, do que com os espaços físicos no qual ele atua (MONTEIRO, 2012, p. 20).

Nesse sentido, o psicólogo deve saber adaptar a postura clínica aos contextos nos quais ele atua, seja nos consultórios, nos hospitais, ou nas instituições governamentais, desenvolvendo um método no qual a escuta clínica deve ser ativa, desse modo, sua atuação irá possibilitar "a criação de um ambiente terapêutico 
em diversos contextos, estando preparado para acolher o sujeito que se encontra imerso no sofrimento psíquico, independente do espaço físico no qual se encontra (MONTEIRO, 2012, p. 20). Muitas vezes, as mulheres que sofrem violência necessitam de um acompanhamento, a fim de desvelarem novos sentidos de sua realidade e superarem as sequelas deixadas pelo processo de submissão, a que são submetidas durante anos. Para isso, de acordo com Monteiro (2012), o profissional terapeuta "deverá primeiramente criar um vínculo terapêutico facilitando um ambiente seguro e confiável para que a mulher consiga compartilhar suas experiências que the causaram sofrimento" (MONTEIRO, 2012, p. 21).

Nesta perspectiva de atendimento é importante que o profissional psicólogo seja acolhedor e faça uma escuta ativa da autoexpressão da mulher. Como dito anteriormente, por vezes, a mulher tende-se a sentir culpada ou responsável pela violência sofrida, esses valores geralmente são atribuídos pelo agressor (GUEDES JÚNIOR; RIBEIRO, 2018, p. 11).

De acordo com Guedes Júnior e Ribeiro (2018), é possível observar, por intermédio de alguns relatos de atendimentos, que muitas mulheres apresentam dificuldades em reconhecer a violência sofrida fora de um padrão naturalizado de um relacionamento. Neste aspecto, o psicólogo pode auxiliar as mulheres a se libertarem de algum sentimento de culpa que possam nutrir diante das agressões sofridas (GUEDES JÚNIOR; RIBEIRO, 2018, p. 12).

Desse modo, quando a mulher começa a se conscientizar da situação que vive e percebe que não é culpada e quem deve ser punido pela agressão é o seu parceiro (seu agressor), espaços de potências podem ser criados para empoderar essa mulher a partir da construção de outras formas de relação que não seja violenta (GUEDES JÚNIOR; RIBEIRO, 2018, p. 12).

Vale ressaltar que, segundo as Referências Técnicas para Atuação de Psicólogas (os) em Programa de Atenção à Mulher em situação de Violência (2013), o papel do psicólogo é o de "promover a reflexão nas mulheres em situação de violência, no sentido de que elas possam reconstruir suas vidas e fazer novas escolhas, é fundamental ter acesso a grande variedade de conceitos e teorias a respeito da violência e a especificidade do gênero" (CFP, 2013, p. 50).

Como consequência da violência, as mulheres podem desenvolver inúmeras doenças crônicas, como dores de cabeça, aumento considerável da pressão arterial, ou até mesmo, sério danos de origem, como traumatismos diversos e deficiências físicas, violência essa, que muitas das vezes, podem afetar o "desenvolvimento cognitivo, social, emocional e afetivo da mulher".

Desse modo, é preciso levar em consideração que os sentimentos de insegurança, de impotência, de fragilização das relações sociais estabelecidas, decorrentes de seu isolamento, de certa forma são comuns, fazendo com que os estados constantes de tristeza, ansiedade e medo, se tornem mais frequentes, dessa forma, considera-se muito comum, nessa fase, o aparecimento da depressão, do transtorno do pânico, do estresse pós-traumático, e do comportamento e ideias autodestrutivas (CFP, 2013, p. 71-72).

Portanto, as consequências das agressões que as mulheres são constantemente submetidas, vão muito além do sofrimento psicológico, que por si só, já é considerável um grande dano à sua saúde, existe também as doenças crônicas advindas de tal agressão. Desse modo, o psicólogo pode intervir prestando uma escuta proveniente da profissão para amenizar os efeitos oriundos da violência, onde as mulheres possam reconstruir suas vidas e aprender a fazer novas escolhas e sem medo, prosseguirem a vida como principal protagonista da sua história.

\section{O papel do psicólogo no atendimento aos agressores}

Dentro desta perspectiva, vale ressaltar que existe também o auxílio psicológico prestado aos agressores, muito emboraé preciso levarem consideração que não são muitos, os agressores que procuram algum tipo de ajuda do Psicólogo, por assumirem um papel de "dominador" frente a sociedade que reforça o machismo. Contudo, o Projeto de Lei do Senado (PLS) n ${ }^{\circ}$ 9, de 2016 (BRASIL, 2016), recebeu um substitutivo da Câmara dos Deputados $\mathrm{n}^{\circ} 11$ de 2018 (BRASIL, 2018), com a promulgação da Lei $\mathrm{n}^{\mathrm{o}} 13.984$ de 03 de abril 2020 (BRASIL, 2020), que alterou a Lei $\mathrm{n}^{\circ} 11.340$, de 07 de agosto de 2006, que "obriga o comparecimento do agressor a programas de recuperação e reeducação com acompanhamento psicossocial, por meio de atendimento individual e/ou em grupo de apoio (BRASIL, 2020). Segundo Monteiro (2012), muitos desses homens, quando buscam algum profissional normalmente são encaminhados pelo poder judiciário, ou outras instituições "como delegacias, abrigos e conselhos". Além disso, alguns por quererem recuperar o relacionamento acreditam que participar dos atendimentos psicológicos sugeridos pelo judiciário podem trazer a companheira de volta ou livrá-los da condenação (MONTEIRO, 2012, p.27).

Junto com o homem vem sendo construído socialmente uma imagem da mulher como sendo um sexo frágil e por isso seria incapaz para desempenhar suas tarefas sociais sem seu auxílio, sendo alvo de uma objetificação. Por isso, repousa o fato de que o agressor não consegue perceber a violência contra sua parceira, esposa ou companheira.

Desse modo, a maioria não se sente responsável pela agressão cometida e por isso acredita não necessitar 
de nenhum tipo de tratamento psicológico, se colocando por vezes, no lugar de vítimas, responsabilizando as mulheres pelo principal problema da relação (MONTEIRO, 2012, p. 27).

$\mathrm{Na}$ perspectiva de auxílio prestado pelo Psicólogo, a esse grupo de indivíduos, cabe a compreensão das reais motivações que levaram os agressores a cometerem tais violências contra a mulher e a subjetivação desses processos machistas presentes socialmente (MONTEIRO, 2012, p. 27).

Contudo, é possível observar que, em tempos remotos, tal agressor era visto como possuidor de algum tipo de psicopatologia, porém, com os avanços crescentes dos estudos relacionados com as agressões ocorridas, chegou-se a compreensão de que a presença de tais distúrbios psiquiátricos, não é necessariamente a causa efetiva da violência investida contra as mulheres, muito embora, a convivência frequente aos ambientes marcados por essa violência, em algum momento, levam os agressores a desenvolverem algum tipo de distúrbios ou psicopatologias (MONTEIRO, 2012, p. 27).

De acordo com Guedes Júnior e Ribeiro (2018), encontram-se entre os possíveis agressores: "maridos, amásios, amantes, namorados atuais, ou, até, exnamorados ou ex-cônjuges". Trazendo um perfil dos agressores, muito embora seja difícil assim estipular, por não existir definidamente os traços de personalidade específicos desses agressores, "é possível identificar algumas características na maioria deles: ideias rígidas a respeito do papel da mulher e do homem na sociedade e família, dificuldade para falar sobre seus sentimentos" (GUEDES JÚNIOR; RIBEIRO, 2018).

Para que haja o trabalho psicoterapêutico de acordo com o contexto desses agressores, o profissional psicólogo precisa estar atento a não emitir nenhum tipo de julgamento de valor sobre tal agressor, para não impossibilitar o tratamento, por quebrar o vínculo terapêutico, ficando prejudicado o trabalho realizado pelo psicólogo. Desse modo, deve-se trabalhar dentro da concepção reflexiva, em contexto mais educacional (MONTEIRO, 2012, p. 28).

Nesse aspecto, "é importante que o autor também esteja em tratamento para compreender os processos implicados na relação violenta e assim ter possibilidades de mudança" (MONTEIRO, 2012, p. 28).

Portanto, acredita-se que as tentativas de relações saudáveis devem ser consideradas válidas, a fim de tornar possível uma convivência respeitosa entre os gêneros. Para isso, o agressor é obrigado a frequentar os centros de educação e reabilitação, conforme determina a Lei n ${ }^{\circ} 13.984$ de 03 de abril 2020 (BRASIL, 2020) a partir do Substitutivo $n^{\circ} 11 / 2018$ (de autoria da Comissão de Direitos Humanos e Legislação Participativa da Câmara dos Deputados - a partir do
PLS n ${ }^{\circ}$ 9/2016) em que, alterando a Lei Maria da Penha $\mathrm{n}^{\circ} 11.340 / 2006$, passa a estabelecer a obrigatoriedade no Artigo $22^{\circ}$, incisos VI - comparecimento do agressor a programas de recuperação e reeducação; e VII acompanhamento psicossocial do agressor, por meio de atendimento individual e/ou em grupo de apoio. (BRASIL, 2020).

\section{Conclusão}

Pretendeu-se com o estudo trazer uma reflexão de caráter educativo, por meio de uma breve exposição de situações que habitam a existência doméstica para contribuir com a prevenção da violência doméstica. Desse modo, compreende-se a relevância do atendimento psicológico, na assistência às mulheres e aos agressores em situação de violência doméstica.

Neste aspecto, este trabalho não tem a presunção de se apresentar como uma regra a ser seguida rigorosamente, mas tem na verdade, a intenção de ampliar o debate em torno do tema: Violência Doméstica, ultrapassando paradigmas sociais de tempos remotos, principalmente os que são relacionados ao gênero e demonstrar de fato, a relevante participação do profissional psicólogo nesse tipo de atendimento.

Desse modo, a atuação do psicólogo deve ser no sentido de intervenção às mulheres em situação de violência - com graves problemas psicológicos e/ou desenvolvimento de doenças crônicas adquiridas por prolongados anos de sofrimento -, com a finalidade de atenuar seus efeitos, permitindo que consigam superá-los, reaprendendo a conviver em sociedade e reconstruindo suas vidas.

Dentro desta perspectiva de auxílio psicoterapêutico prestado, cabe à mulher ressignificar a condição que lhe foi imposta pelo seu agressor e, tomar uma posição diante de tudo, não permitindo que sua autoestima seja totalmente destruída, mas pelo contrário, deve encontrar forças e superação.

Observou-se também, que a "cultura machista" perpetuada há décadas, repousa no fato de que os homens acreditam que detém poder, justificando suas agressões. Por isso, a necessidade de uma atuação de educação, por meio de grupos nos centros de apoio, por exemplo. Desse modo, com a finalidade de coibir e prevenir tal agressão, mediante um dispositivo legal, é que surge no cenário brasileiro, a Lei Maria da Penha, representando um avanço inquestionável, no combate a violência doméstica, garantindo à mulher em situação de violência as garantias inerentes na Lei ${ }^{\circ} 11.340$ de 07 de agosto de 2006 com seus substitutos.

Portanto, que a conjectura apresentada neste trabalho, seja promotora de um processo reflexivo, permitindo aos psicólogos em suas assistências às mulheres em situação de violência doméstica que 
tenham seus efeitos atenuados, a fim de reconstruírem suas vidas, reaprendendo a fazer novas escolhas sem medo ou culpa, tornando-se protagonistas da sua própria história.

\section{Referências}

BANDEIRA, Lourdes Maria. Violência de Gênero: a construção de um campo teórico e de investigação. Revista Sociedade e Estado. n. 29, v. 2. p. 449-469, 2014. Disponível em: http://www.scielo.br/scielo.php?script=sci arttext\&pid=S0102-69922014000200008. Acesso em: 15 Out. 2019.

BRASIL. Lei $\mathrm{n}^{\circ} 11.340$ de 07 de Agosto de 2006 - Lei Maria da Penha. Disponível em: http://www.planalto.gov.br/ccivil 03/ ato2004-2006/2006/ lei/111340.htm. Acesso em 20 Out. 2019.

. Lei $n^{\circ} 13.104$ de 9 de março de 2015. Disponível em: http://www. planalto.gov.br/ccivil_03/_ato2015-2018/2015/lei/113104.htm. Acesso: 15 Abr. 2015.

Senado Federal. Projeto de Lei do Senado no 9 de 2016 - De autoria da Comissão de Direitos Humanos e Legislação Participativa. Disponível em: https://www25.senado.leg.br/web/atividade/materias/-/materia/124675. Acesso em: 24 Nov. 2019

. Câmara dos Deputados. Substitutivo da Câmara dos Deputados n ${ }^{\circ}$ 11 de 2018 - De autoria da Comissão de Direitos Humanos e Legislação Participativa. Disponível em: https://www25.senado.leg.br/web/atividade/ materias/-/materia/134960. Acesso em: 15 Abr. 2020.

Disponível em: http:/www.planalto.gov.br/ccivil_03/_Ato20192022/2020/Lei/L13984.htm. Acesso: 15 Abr 2020

CASIQUE, Letícia Casique; FUREGATO, Antonia Regina Ferreira. Violência contra mulheres: Reflexões Teóricas. Rev Latino-am Enfermagem. n. 14. v. 6. Nov./Dez., 2006. Disponível em: http://www.scielo.br/pdf/rlae/ v14n6/pt_v14n6a18.pdf. Acesso em: 26 Nov. 2019.

CORTIZO, María del Carmem; GOYENECHE, Priscila Larratea. Judiciarização do privado e "violência" contra a mulher. Revista Katál, Florianópolis, n. 1, v. 13, p. 102-109, jan./jun.,2010. Disponível em: https:// doi.org/10.1590/S1414-49802010000100012. Acesso em: 26 Nov. 2019.

CONSELHO FEDERAL DE PSICOLOGIA (CFP). Referências técnicas para atuação de psicólogas (os) em Programas de Atenção à Mulher em situação de violência. Ano: 2013. Disponível em: http://www.crpsp.org. br/portal/comunicacao/artes-graficas/arquivos/2013-CREPOP-ViolenciaMulher.pdf. Acesso em: 24 Out. 2019.

GUEDES JÚNIOR, Ercedilio; RIBEIRO, Jaqueline Valéria. Atendimento Psicológico as Mulheres Vítimas de Violência Doméstica. Trabalho de Conclusão de Curso. Psicologia da Faculdade de Pimenta Bueno - FAP, Pimenta Bueno - RO, 2018. Disponível em: https://fapb.edu.br/wp-content/ uploads/sites/13/2018/02/ed7/4.pdf. Acesso em: 20 Out. 2019.

KARLINSKI, Elisangela. Gênero na Câmara Legislativa do Distrito Federal: um olhar sobre a ação parlamentar feminina. Trabalho de Conclusão de Curso. Programa de Curso de Especialização em Política e Representação Parlamentar, Pós-Graduação do Centro de Formação, Treinamento e Aperfeiçoamento da Câmara dos Deputados/CEFOR, 2012. Disponível em: http://bd.camara.gov.br/bd/bitstream/handle/bdcamara/13156/genero_ camara_karlinski.pdf?sequence=4. Acesso: 15 Out. 2019.

MONTEIRO, Fernanda Santos. O papel do Psicólogo no atendimento às Vítimas e Autores de Violência Doméstica. Trabalho de Conclusão de Curso. Curso de Bacharelado em Psicologia pela Faculdade de Ciências da Educação e Saúde do Centro Universitário de Brasília - UniCEUB, Brasília, 2012. Disponível em: https://repositorio.uniceub.br/jspui/bitstream/1234567 89/2593/3/20820746.pdf. Acesso: 20 Out. 2019.

MORAES, Camila de Freitas; SILVA, Rafaely Cristina Santos da; AVIZ, Taynah Silva de. Lei Maria da Penha e Lei do Feminicídio: um avanço que se faz necessário diante das relações assimétricas na violência de Gênero. Psicologia.pt. 2017. Disponível em: https://www.psicologia.pt/artigos/ textos/A1133.pdf. Acesso em: 15 Out. 2019.

MOREIRA, Virginia; BORIS, Georges Daniel Janja Bloc; VENÂNCIO, Nadja. O estigma da violência sofrida por mulheres na relação com seus parceiros íntimos. Psicologia \& Sociedade; n. 23 v. 2. p. 398-406, 2011.
Disponível em: http://www.scielo.br/pdf/psoc/v23n2/a21v23n2.pdf. Acesso em: 15 Out. 2019.

OLIVEIRA, Andressa Porto de. A eficácia da Lei Maria da Penha no combate à violência doméstica contra a mulher. Trabalho de Conclusão. Curso de Direito da Universidade de Santa Cruz do Sul, UNISC, 2015. Disponível em: https://repositorio.unisc.br/jspui/bitstream/11624/851/1/Andressa $\% 20$ Porto\%20de\%20Oliveira.pdf. Acesso: 21 Out. 2019.

PEREIRA, Elizângela S.; PEREIRA, Daisymar S. Feminicídio - Lei n ${ }^{\circ}$ 13.104 de 09 de março de 2015. Feminicídio no Brasil: estatísticas mostram que Brasil ó o quinto país que mais matam mulheres. Disponível em: https:// jus.com.br/artigos/62399/feminicidio-lei-n-13-104-de-9-de-marco-de-2015. Acesso: 21 Out. 2019.

TELES, Maria Amélia de Almeida; MELO, Mônica de. O que é violência contra a mulher? Coleção Primeiros Passos. São Paulo: Brasiliense, 2003. WALKER, Lenore. O ciclo de violência de Lenore Walker. Artigo: 2018. Disponível em: https://amenteemaravilhosa.com.br/ciclo-da-violencialenore-walker/. Acesso em 15 Abr. 2020 